\title{
Concurrent and Post COVID-19 Ophthalmological Implications
}

\author{
Tamer Wasfy \\ Mohamed A Eldesouky \\ Yasser Serag $(\mathbb{D}$ \\ Hazem A Elbedewy \\ Ophthalmology Department, Tanta \\ University, Tanta, Egypt
}

Correspondence: Hazem A Elbedewy Ophthalmology Department, Tanta University, Tanta, Egypt

Tel +20 I 276732425

Email hazemelbedewy@yahoo.com
Background and Aim: COVID-19 infection is a respiratory disease but it can have ophthalmological manifestations as well. This study aimed to investigate the ophthalmological implications of COVID-19 either during the course of the disease or after recovery.

Methods: A retrospective study included the records of 425 COVID-19 patients, proved by positive PCR swabs. The records were collected from three isolation hospitals in Gharbeya Governorate, Egypt.

Results: The mean age of the studied group was $41.73 \pm 13.59$, and $216(50.8 \%)$ of them were males. One hundred and thirty one (30.8\%) patients had ophthalmological manifestations. Among the entire patients, the most common ophthalmological presentation was conjunctivitis in 111 patients $(26.1 \%)$, followed by neuro-retinal affection in $9(2.1 \%)$, secondary fungal orbital cellulitis in $6(1.4 \%)$, episcleritis in $3(0.7 \%)$ and keratitis in 2 $(0.5 \%)$ patients. All of the observed ophthalmological implications occurred either during the course of the disease (concurrent) or after recovery, except for the fungal orbital cellulitis which occurred only after recovery.

Conclusion: COVID-19 could cause different eye manifestations. Recovery from the main disease does not guarantee eye safety, especially in high-risk patients.

Keywords: COVID-19, conjunctivitis, orbital cellulitis, retinal vein occlusion, papillophlebitis

\section{Introduction}

Three members of the corona virus family can cause severe respiratory illness that may lead to death. They are the SARS-CoV-2, SARS-CoV, and MERSCoV. ${ }^{1}$ Beside the typical respiratory manifestations of COVID-19, other body systems including the eye are now known to be affected by SARS CoV virus as well. $^{2-5}$ The virus can affect the eye in several ways and ocular manifestations have a wide range. ${ }^{6-8}$ This may include conjunctivitis, ${ }^{9-11}$ keratitis, $^{12}$ episcleritis $^{13}$ and retinal hemorrhage or cotton wool spots. ${ }^{14-16}$ The published reports of the ocular manifestations caused by COVID-19 showed different incidence, but generally it was low. ${ }^{1}$

As COVID-19 pandemic is still going, on new symptoms, signs and postinfection complications become apparent. These complications could affect the heart, liver, brain and other organs, however, the respiratory complications remain the main cause of death. ${ }^{17}$

After more than one year of COVID-19 in Egypt, this study retrospectively reviewed the records of COVID-19 patients to find out the ophthalmological manifestations of those patients. 


\section{Patients and Methods}

A retrospective study conducted in 3 isolation hospitals, Gharbeya Governorate, covering the period of April 2020 till April 2021, in the Egyptian Delta. It was approved by the institutional ethical committee, Faculty of Medicine, Tanta University and was done according to the declaration of Helsinki and its later amendment. All the included patients were COVID-19 confirmed cases by real-time PCR testing and were treated according to the treatment protocol of the Egyptian Ministry of Health and Population.

All the data were used only for research purposes and were kept confidential. For this type of study, formal consent was not required. Patients whose images were included in this article, provided an informed consent to publish their images with brief case description.

The health records of 447 patients were eligible to be included in this study. Two authors collected the data primarily and the other two checked the data one more time. Twenty-two incomplete records were excluded and 425 valid records were included in this study.

The collected data included the ocular symptoms as reported by the patients and the results of anterior segment examination, using the slit lamp and dilated fundus examinations, as reported by the ophthalmologists. Two authors who are experts in ophthalmological investigations reviewed the results of any available ocular investigations. For the systematic manifestations, these were recorded in every patient's data file by an internist. This included general and respiratory manifestations, severity of COVID-19 disease, past history of chronic illness and any COVID-19 related complications. COVID-19 disease severity was defined according to the World Health Organization interim guidance released March $2020{ }^{18}$

\section{Statistical Analysis}

The data were collected on Excel sheet and were presented as mean, standard deviation (SD), numbers (No.) and percentages $(\%)$. Chi-square test $(\chi 2)$ was used to study association between qualitative variables. Whenever any of the expected cells were less than five, Fischer's Exact test was used. The statistical analysis was performed by SPSS statistical package version 23 (SPSS Inc. Released 2015. IBM SPSS statistics for windows, version 23.0, Armonk, NY, IBM Corp.). Two-sided P- value of $<0.05$ was considered statistically significant.

\section{Results}

The study included 425 records of patients with confirmed COVID-19 infection. Their mean age was $41.73 \pm 13.59$ years (ranging from 19 to 85 years), 50.8\% were males and $53.9 \%$ were living in urban areas. About 30.8\% (131 patients) had ophthalmological manifestations. Among the entire group of patients, conjunctivitis was presented in 111 $(26.1 \%)$ patients, keratitis in two $(0.5 \%)$, episcleritis in three $(0.7 \%)$, neuro-retinal affection in nine $(2.1 \%)$, and secondary fungal orbital cellulitis in six (1.4\%) patients (Table 1$)$.

Table 2 details the patients' characteristics according to their ophthalmological diagnosis.

Patients with COVID-19 related conjunctivitis were presented by conjunctival hyperemia, foreign body sensation and tearing. The condition was temporary in all the affected patients and resolved within 10 days from the start of the illness with simple treatment in the form of combined antibiotic/ steroid and artificial tears. Conjunctivitis was the presenting symptoms of COVID-19 disease in 47 patients (10.4\%).

Episcleritis and keratitis were diagnosed in three and two patients respectively. Patients with episcleritis recovered completely within two weeks using artificial tears and local non-steroid anti-inflammatory eye drops. However, patients with keratitis required about four weeks of treatment with artificial tears and corticosteroid eye drops to have partial improvement.

Retinal and neuro-ophthalmological involvement was confirmed by Optical Coherence Tomography (OCT)

Table I Number and Percentage Distribution of Different Ophthalmological Diagnoses Among the Studied Patients

\begin{tabular}{|l|l|l|l|}
\hline Diagnosis & Number & \% from the Entire Group (n=425) & $\begin{array}{l}\text { \% from Ophthalmological Affected } \\
\text { Patients }(\mathbf{n = 1 3 1 )}\end{array}$ \\
\hline Conjunctivitis & $1 \mathrm{II}$ & 26.1 & 84.7 \\
Keratitis & 2 & 0.5 & 4.7 \\
Episcleritis & 3 & 0.7 & 2.3 \\
Retina and neuro-retinal & 9 & 2.1 & 6.9 \\
Secondary fungal orbital cellulitis & 6 & 1.5 & 4.6 \\
\hline
\end{tabular}


Table 2 Patients' Characteristics According to Their Ophthalmological Diagnosis

\begin{tabular}{|c|c|c|c|c|c|c|}
\hline Character & $\begin{array}{l}\text { Conjunctivitis } \\
(n=111)\end{array}$ & $\begin{array}{l}\text { Keratitis } \\
(n=2)\end{array}$ & $\begin{array}{l}\text { Episcleritis } \\
(n=3)\end{array}$ & $\begin{array}{l}\text { Neuro-Retinal } \\
\text { Affection }(n=9)\end{array}$ & $\begin{array}{l}\text { Secondary Fungal Orbital } \\
\text { Cellulitis }(n=6)\end{array}$ & $\begin{array}{l}\text { Entire Patients } \\
(n=425)\end{array}$ \\
\hline Age in years (mean $\pm S D$ ) & $40.68 \pm 13.08$ & $40.00 \pm 13.0$ & $46.0 \pm 15.55$ & $48.22 \pm 12.29$ & $46.83 \pm 15.36$ & $41.73 \pm 13.59$ \\
\hline Range & $19.0-75.0$ & $320-55.0$ & $35.0-57.0$ & $32.0-72.0$ & $25.0-67.0$ & $19.0-85.0$ \\
\hline \multicolumn{7}{|l|}{ Gender } \\
\hline Male & $55(49.5)$ & $2(100.0)$ & I (33.3) & $4(44.4)$ & $3(50.0)$ & $216(50.8)$ \\
\hline Female & $56(50.5)$ & $0(0.0)$ & $2(66.7)$ & $5(55.6)$ & $3(50.0)$ & $209(49.2)$ \\
\hline Pre-existing comorbidities & $15(13.5)$ & I (50.0) & I (33.3) & $4(44.4)$ & $6(100.0)$ & $56(13.2)$ \\
\hline
\end{tabular}

scans for the nine affected patients. Cotton wool spots were seen by fundus examination in $5(55.6 \%)$ of them. The OCT scans showed mild retinal edema and/or retinal infarcts with hyper-reflective lesions at the level of ganglion cell layer. Retinal affection in the form of cotton wool spots was also a temporary condition and self-limited. It resolved in most patients within five weeks. They were followed up by repetitive OCT scans every 2 weeks. Only one patient developed central retinal vein occlusion with anterior ischemic optic neuropathy (papillophlebitis) 4 weeks after recovery. He was male aged 57 years without any known history of chronic illness before COVID-19 infection. His scans showed retinal edema, cystoid macular edema, neurosensory detachment and optic disc hyperemia (Figure 1).

Six patients showed confirmed orbital fungal cellulitis after recovery from COVID-19 infection. All of them had at least one pre-existing risk factor (e.g. diabetes). All of them were presented by atypical orbital apex syndrome and two showed also black skin eschars. Figure 2 shows the clinical presentation and imaging of one of those patients.

There was no significant association between different clinical manifestations or complications of COVID-19 (fever, headache, loss of smell and taste, body aches, disease severity and mechanical ventilation) and its related ophthalmological implications ( $\mathrm{p}=0.773,0.252,0.110,0.569,0.104$ and 0.068 respectively). This is detailed in Table 3 .

\section{Discussion}

Since the appearance of COVID-19 pandemic, ophthalmological manifestations were reported very early in many cases.

The commonest ophthalmological manifestation encountered in this study was conjunctivitis. About one third of the included patients complained of conjunctivitis either uni- or bi-laterally. Most of them reported conjunctivitis early in the course of the disease, while some others could not exactly tell the onset of conjunctival symptoms.

Wu et al ${ }^{10}$ published a brief report on 38 patients with clinically confirmed COVID-19 from Hubei, China. Twelve of their patients (31.6\%) had ocular manifestations in the form of conjunctivitis presented with hyperemia, chemosis and epiphora, only one patient was presented by conjunctivitis as the first symptom of COVID-19. They noted also, that ocular manifestations were associated with more severe COVID-19 cases. Another case report for 53 year old man was presented with mild eye irritation, erythema and conjunctivitis without any associated systemic manifestations. The next day, this man was tested positive by PCR testing for COVID-19 during routine travel investigation. ${ }^{9}$ Pirraglia et al,${ }^{16}$ reported bilateral conjunctivitis in only $7 \%$ of their cohort, which consisted of 43 patients with COVID-19 pneumonia. Loon et $\mathrm{al}^{19}$ studied 8 patients with possible SARS-CoV and could detect the virus in tears of 3 of them within 9 days of the onset of the disease.

In this study, we had one patient with unilateral papillophlebitis. He was a middle aged male presented with acute painless diminution of vision 1 month after recovery of COVID-19 infection. The patient was not known to have any chronic co-morbidities before getting infected with COVID-19. His manifestations started when he abruptly stopped his anti-coagulant without a permission from his physician.

Early reports of 2020 raised the suspicion of the coagulopathy and antiphospholipid syndrome in patients with COVID-19. ${ }^{20}$ After that, many published papers appeared reporting cases of vein occlusion in COVID-19 patients around the world. ${ }^{21}$

Among our patients, eight (1.9\%) had pure retinal lesions. All of them had retinal thickening and hyper-reflective 


\begin{tabular}{|c|c|c|c|}
\hline Radial Report & 3D OCT-2000FA & Ver.8.43) & Print Date $: 2 / 13 / 2021 \approx T O P C O N$ \\
\hline ID : 33-2-2021 & Ethnicity: Cauce & & Technician : \\
\hline Name: & $\begin{array}{l}\text { Gender: Male } \\
\text { DOB : } 1 / 1 / 1964\end{array}$ & Age : 57 & $\begin{array}{l}\text { Fixation : OD(R) Macula } \\
\text { Scan : Radial }(6.0 \mathrm{~mm}-1024 \times 12)\end{array}$ \\
\hline
\end{tabular}

OD(R) TopQ Image Quality : 28 mode : Fine(1.1.0) Capture Date : $2 / 13 / 2021$ O.E.M:1.000x
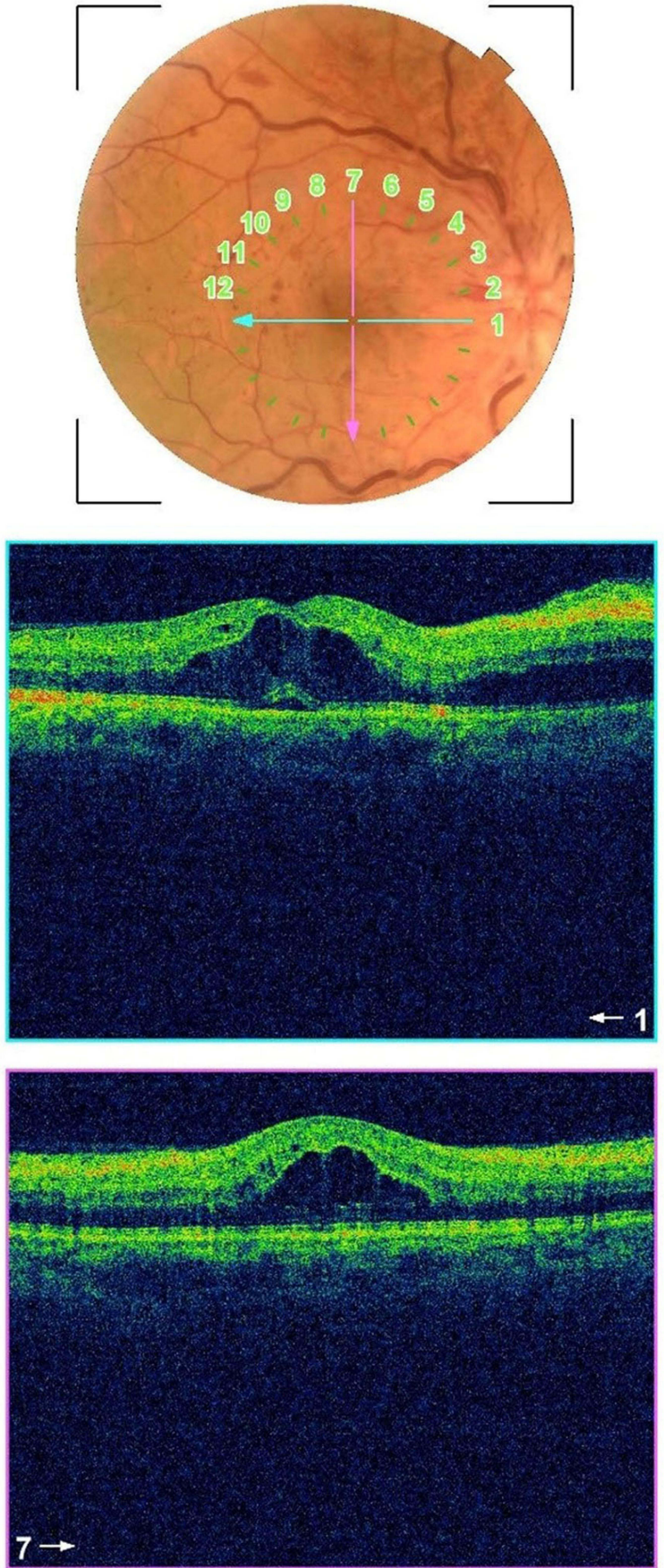

Comments

\section{Retinal thickness map ILM - OS/RPE / Red-free}

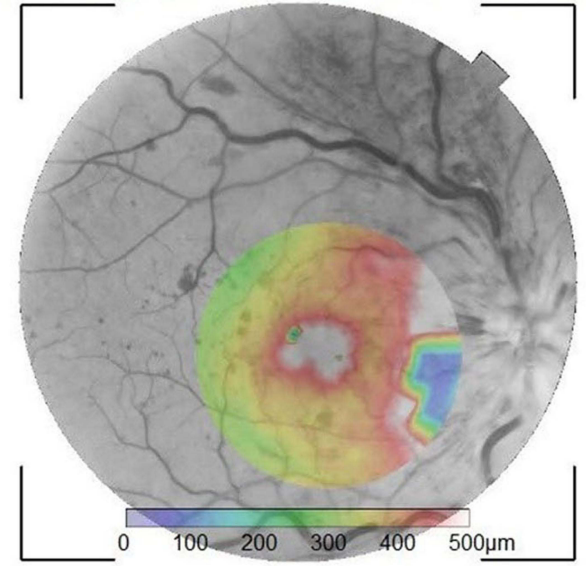

Retinal thickness ILM - OS/RPE ( $\mu \mathrm{m})$ ETDRS

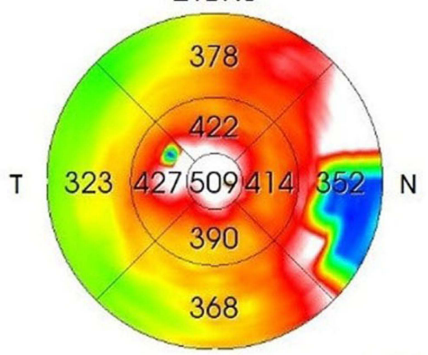

Average Thickness $(\mu \mathrm{m})$

372.4

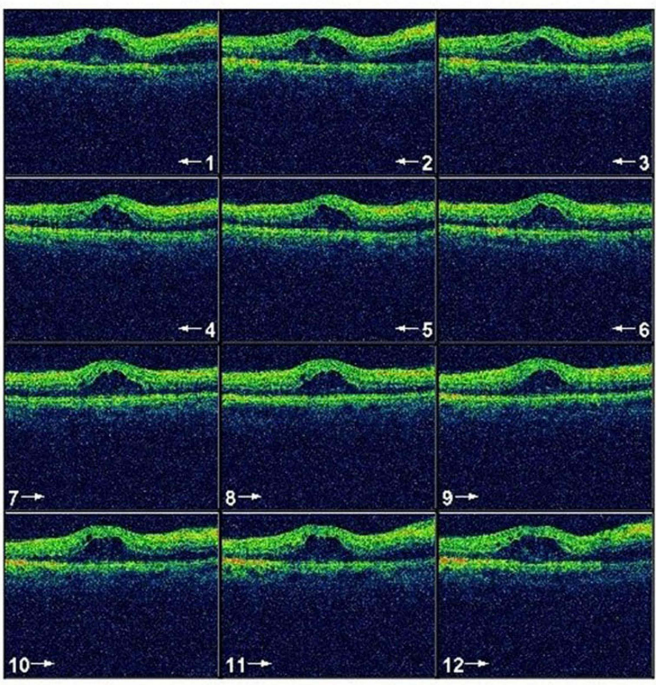

Signature :

Date :

Figure I Male patients 57 years old. He came to the ophthalmology clinic I months after recovery from COVID-19 infection, complaining of sudden diminution of vision. His optic disc was swollen and edematous with engorged vessels. His macular OCT scans show cystoid macular edema (CME) continuous with the disc edema with presence of neurosensory detachment (NSD). 


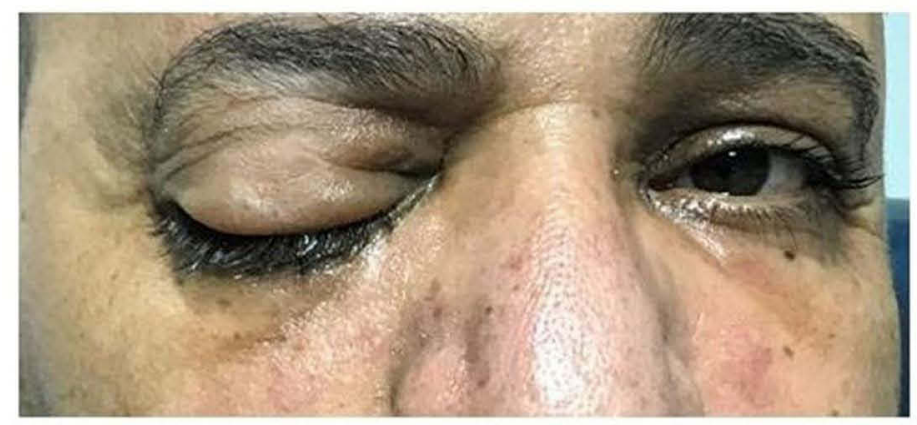

A

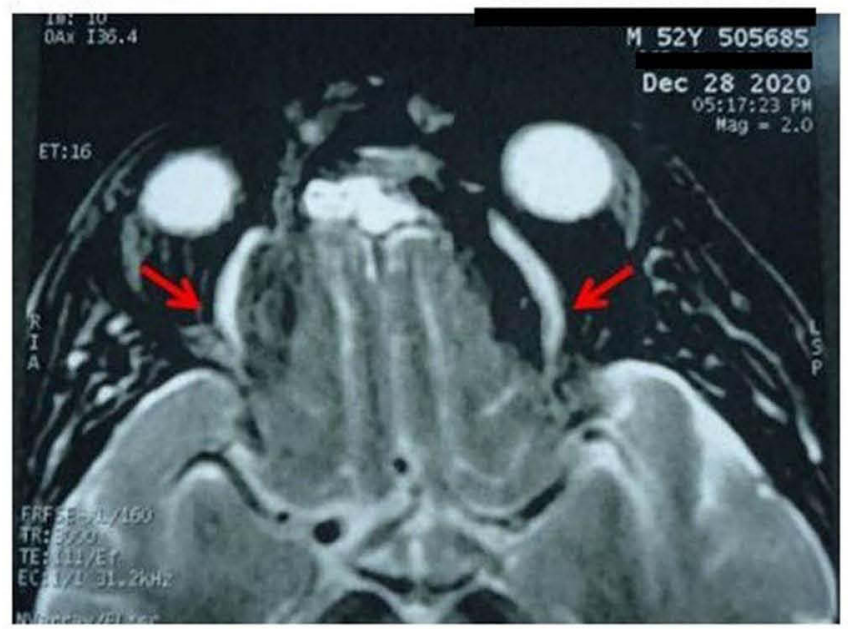

C

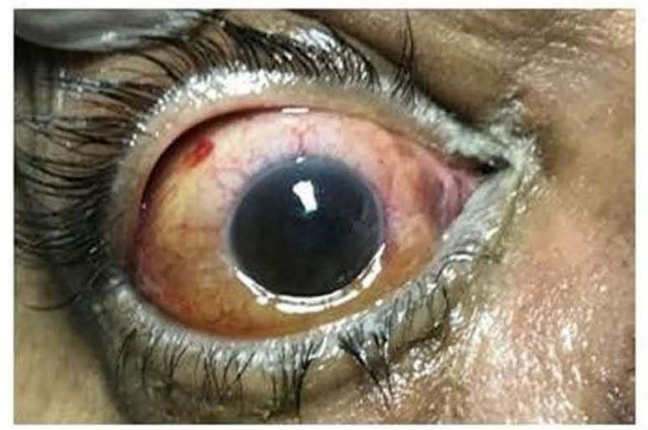

B

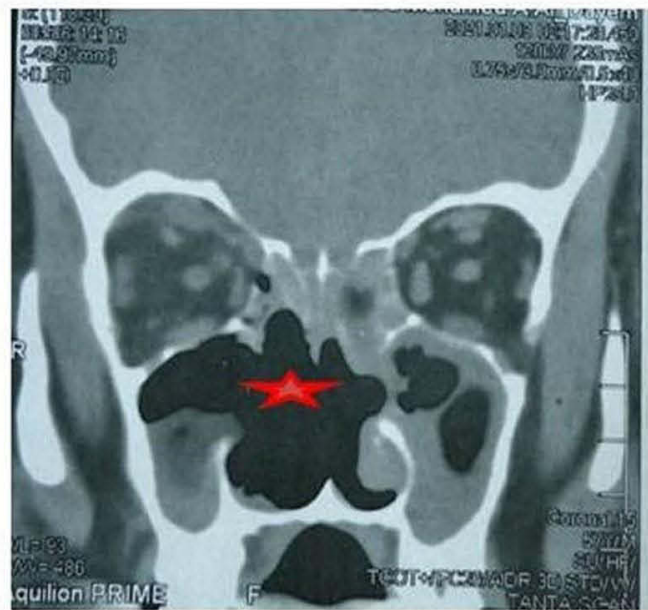

D

Figure 2 Male 52 year old diabetic patient just recovered from COVID presented with complete orbital apex syndrome (A and B). T2 FAT SAT MRI bilateral congested superior ophthalmic veins; red arrows (C). Coronal CT scan orbit and sinuses showing massive bone destruction red star (D).

patches of the middle retinal layers. Their OCT angiography scans revealed focal areas of low blood flow, due to ischemia, at the level of deep capillary plexus. This percentage was much lower than what was reported by Landecho et al. ${ }^{22}$
They found retinal Cotton Wool Spots (CWS) in $6(22 \%)$ out of 27 confirmed COVID-19 patients. They concluded that CWS are very related to endothelial disease and such patients are prone to acute vascular complications. Pirraglia et $\mathrm{al}^{16}$

Table 3 COVID-19 Disease Manifestations Among Different Ophthalmological Implications

\begin{tabular}{|c|c|c|c|c|c|c|}
\hline Disease Manifestations & $\begin{array}{l}\text { Conjunctivitis } \\
(n=I I I)\end{array}$ & Keratitis $(n=2)$ & $\begin{array}{l}\text { Episcleritis } \\
(n=3)\end{array}$ & $\begin{array}{l}\text { Neuro-Retinal } \\
\text { Affection }(n=9)\end{array}$ & $\begin{array}{l}\text { Secondary Fungal } \\
\text { Orbital Cellulitis }(n=6)\end{array}$ & $P$ value \\
\hline Fever & $91(81.9)$ & $2(100.0)$ & $2(66.7)$ & $7(77.8)$ & $4(66.7)$ & 0.773 \\
\hline Headache & $76(68.5)$ & $2(100.0)$ & $2(66.7)$ & $9(100.0)$ & $5(83.3)$ & 0.252 \\
\hline Loss of smell and taste & $39(35.1)$ & I (50.0) & $2(66.7)$ & $7(77.8)$ & $2(33.3)$ & 0.110 \\
\hline Body aches & $56(50.4)$ & $2(100.0)$ & I (33.3) & $5(55.6)$ & $4(66.7)$ & 0.569 \\
\hline $\begin{array}{l}\text { Disease severity } \\
\text { Mild/Mod } \\
\text { Sever/Critically ill }\end{array}$ & $\begin{array}{l}79(71.2) \\
32(28.8)\end{array}$ & $\begin{array}{l}2(100.0) \\
0(0.0)\end{array}$ & $\begin{array}{l}3(100.0) \\
0(0.0)\end{array}$ & $\begin{array}{l}8(88.9) \\
1(11.1)\end{array}$ & $\begin{array}{l}2(33.3) \\
4(33.3)\end{array}$ & 0.104 \\
\hline Mechanical ventilation & $25(22.5)$ & $0(0.0)$ & $0(0.0)$ & $0(0.0)$ & $4(33.3)$ & 0.068 \\
\hline
\end{tabular}


reported one case of unilateral posterior chorioretinitis among their cohort. They explained this case by opportunistic fungal infection. Retinitis was also reported in an 11 year old child. His fundus examination showed retinal vasculitis with perivascular infiltrate and retinal exudates. These lesions resolved completely in 2 weeks without any signs of residual atrophy. $^{23}$

Post-COVID-19 fungal orbital cellulitis was evident in six of our patients. Four of them were diabetics, one was cardiac and one was receiving chemotherapy. They all received corticosteroids in their COVID-19 treatment regimen. These circumstances were very close to what reported by Sarkar et al, ${ }^{24}$ who diagnosed 10 cases of concurrent COVID-19 patients complicated with orbital mucormycosis. They were all diabetics and received intravenous dexamethasone during their course of treatment. Some other studies reported rhino-orbital mucormycosis in patient with concurrent of post-COVID 19 infection. All of the reported cases were immunocompromised, mainly diabetics, and had steroids during their course of treatment, ${ }^{25-28}$ however, Maini et $\mathrm{al}^{29}$ reported one case of post COVID-19 mucormycosis without any history of diabetes or immunocompromising condition.

None of the ophthalmological implications observed in this study was related to a specific COVID-19 clinical manifestation or complications. Invernizzi et $\mathrm{al}^{15} \mathrm{did}$ not find any significant association between retinal findings in COVID-19 patients and their demographic, systemic disease, lab or clinical parameters.

\section{Conclusion}

COVID-19 can cause serious ophthalmological complications even after the end of the respiratory disease. The patients should be followed up regularly after recovery for at least 3 months especially high risk and diabetic patients. Any unusual ophthalmological sign or symptom could be an alarming sign for a serious underlying condition.

\section{Disclosure}

The authors report no conflicts of interest in this work.

\section{References}

1. Chen Z, Yuan G, Duan F, et al. Ocular involvement in Coronavirus disease 2019: up-to-date information on its manifestation, testing, transmission, and prevention. Front Med. 2020;7:569126. doi:10.3389/fmed.2020.569126

2. Guan WJ, Ni ZY, Hu Y, et al. Clinical characteristics of Coronavirus disease 2019 in China. $N$ Engl J Med. 2020;382(18):1708-1720. doi:10.1056/NEJMoa2002032
3. Huang C, Wang Y, Li X, et al. Clinical features of patients infected with 2019 novel coronavirus in Wuhan, China [published correction appears in Lancet. 2020 Jan 30]. Lancet. 2020;395(10223):497-506. doi:10.1016/S0140-6736(20)30183-5

4. Romero-Sánchez CM, Díaz-Maroto I, Fernández-Díaz E, et al. Neurologic manifestations in hospitalized patients with COVID-19: the ALBACOVID registry. Neurology. 2020;95(8):e1060-e1070. doi:10.1212/WNL.0000000000009937

5. High B, Hixon AM, Tyler KL, et al. Neurology and the COVID-19 pandemic: gathering data for an informed response. Neurol Clin Pract. 2021;11(2):e48-e63. doi:10.1212/CPJ.0000000000000908

6. Badawi AE, Elsheikh SS, Addeen SZ, et al. An ophthalmic insight into novel coronavirus 2019 disease: a comprehensive review of the ocular manifestations and clinical hazards. $J$ Curr Ophthalmol. 2020;32(4):315-328. doi:10.4103/JOCO.JOCO_255_20

7. Bertoli F, Veritti D, Danese C, et al. Ocular findings in COVID-19 patients: a review of direct manifestations and indirect effects on the eye. J Ophthalmol. 2020;2020:4827304. doi:10.1155/2020/4827304

8. Aggarwal K, Agarwal A, Jaiswal N, et al. Ocular surface manifestations of coronavirus disease 2019 (COVID-19): a systematic review and meta-analysis. PLoS One. 2020;15(11):e0241661. doi:10.1371/ journal.pone.0241661

9. Ahuja AS, Farford BA, Forouhi M, et al. The ocular manifestations of COVID-19 through conjunctivitis. Cureus. 2020;12(12):e12218. doi: $10.7759 /$ cureus. 12218

10. Wu P, Duan F, Luo C, et al. Characteristics of ocular findings of patients with Coronavirus disease 2019 (COVID-19) in Hubei Province, China. JAMA Ophthalmol. 2020;138(5):575-578. doi:10.1001/jamaophthalmol.2020.1291

11. Chen L, Liu M, Zhang Z, et al. Ocular manifestations of a hospitalised patient with confirmed 2019 novel coronavirus disease. $B r \quad J$ Ophthalmol. 2020;104(6):748-751. doi:10.1136/ bjophthalmol-2020-316304

12. Navel V, Chiambaretta F, Dutheil F. Haemorrhagic conjunctivitis with pseudomembranous related to SARS-CoV-2. Am J Ophthalmol Case Rep. 2020;19:100735. doi:10.1016/j.ajoc.2020.100735

13. Bostanci Ceran B, Ozates S. Ocular manifestations of coronavirus disease 2019. Graefes Arch Clin Exp Ophthalmol. 2020;258 (9):1959-1963. doi:10.1007/s00417-020-04777-7

14. Marinho PM, Marcos AAA, Romano AC, et al. Retinal findings in patients with COVID-19. Lancet. 2020;395(10237):1610. doi:10.1016/S0140-6736(20)31014-X

15. Invernizzi A, Torre A, Parrulli S, et al. Retinal findings in patients with COVID-19: results from the SERPICO-19 study. EClinicalMedicine. 2020;27:100550. doi:10.1016/j.eclinm.2020.100550

16. Pirraglia MP, Ceccarelli G, Cerini A, et al. Retinal involvement and ocular findings in COVID-19 pneumonia patients. Sci Rep. 2020;10 (1):17419. doi:10.1038/s41598-020-74446-6

17. Danthuluri V, Grant MB. Update and recommendations for ocular manifestations of COVID-19 in adults and children: a narrative review. Ophthalmol Ther. 2020;9(4):853-875. doi:10.1007/s40123020-00310-5

18. World Health Organization. Clinical management of Severe Acute Respiratory Infection (SARI) when COVID-19 disease is suspected interim guidance; 2020. Available from: https://apps.who.int/iris/bit stream/handle/10665/331446/WHO-2019-nCoV-clinical-2020.4-eng. pdf? sequence $=1$ \&isAllowed=y. Accessed March 13, 2020.

19. Loon SC, Teoh SC, Oon LL, et al. The severe acute respiratory syndrome coronavirus in tears. $\mathrm{Br} J$ Ophthalmol. 2004;88 (7):861-863. doi:10.1136/bjo.2003.035931

20. Zhang Y, Xiao M, Zhang S, et al. Coagulopathy and antiphospholipid antibodies in patients with Covid-19. N Engl J Med. 2020;382(17): e38. doi:10.1056/NEJMc2007575

21. Sheth JU, Narayanan R, Goyal J, et al. Retinal vein occlusion in COVID-19: a novel entity. Indian $J$ Ophthalmol. 2020;68 (10):2291-2293. doi:10.4103/ijo.IJO_2380_20 
22. Landecho MF, Yuste JR, Gándara E, et al. COVID-19 retinal microangiopathy as an in vivo biomarker of systemic vascular disease? J Intern Med. 2021;289(1):116-120. doi:10.1111/joim.13156

23. Fernández Alcalde C, Granados Fernández M, Nieves Moreno M, et al. COVID-19 ocular findings in children: a case series. World J Pediatr. 2021;17(3):329-334. doi:10.1007/s12519-021-00418-z

24. Sarkar S, Gokhale T, Choudhury SS, et al. COVID-19 and orbital mucormycosis [published correction appears in Indian J Ophthalmol. 2021 Jul;69(7):1978]. Indian J Ophthalmol. 2021;69(4):1002-1004. doi:10.4103/ijo.IJO_3763_20

25. Bayram N, Ozsaygilı C, Sav H, et al. Susceptibility of severe COVID-19 patients to rhino-orbital mucormycosis fungal infection in different clinical manifestations. Jpn J Ophthalmol. 2021;65 (4):515-525. doi:10.1007/s10384-021-00845-5
26. Mehta S, Pandey A. Rhino-orbital mucormycosis associated with COVID-19. Cureus. 2020;12(9):e10726. doi:10.7759/cureus.10726

27. Awal S, Biswas S, Awal S. Rhino-orbital mucormycosis in COVID19 patients - a new threat? Egypt J Radiol Nucl Med. 2021;52(152). doi:10.1186/s43055-021-00535-9

28. El-Kholy NA, El-Fattah AMA, Khafagy YW. Invasive fungal sinusitis in post COVID-19 patients: a new clinical entity [published online ahead of print, 2021 May 19]. Laryngoscope. 2021. doi:10.1002/lary.29632

29. Maini A, Tomar G, Khanna D, Kini Y, Mehta H, Bhagyasree V. Sinoorbital mucormycosis in a COVID-19 patient: a case report. Int J Surg Case Rep. 2021;82:105957. doi:10.1016/j. ijscr.2021.105957
Clinical Ophthalmology

\section{Publish your work in this journal}

Clinical Ophthalmology is an international, peer-reviewed journal covering all subspecialties within ophthalmology. Key topics include: Optometry; Visual science; Pharmacology and drug therapy in eye diseases; Basic Sciences; Primary and Secondary eye care; Patient Safety and Quality of Care Improvements. This journal is indexed on PubMed

Submit your manuscript here: https://www.dovepress.com/clinical-ophthalmology-journal
Dovepress

Central and CAS, and is the official journal of The Society of Clinical Ophthalmology (SCO). The manuscript management system is completely online and includes a very quick and fair peer-review system, which is all easy to use. Visit http://www.dovepress.com/ testimonials.php to read real quotes from published authors. 